\title{
Study of cellulose-lysozyme interactions aimed to a controlled release system for bioactives
}

\author{
E. Mascheroni - G. Capretti - S. Limbo • \\ L. Piergiovanni
}

Received: 24 February 2012/ Accepted: 20 August 2012

(C) Springer Science+Business Media B.V. 2012

\begin{abstract}
The potential use of cellulose based materials for active food packaging applications was explored. For this purpose, the sorption of lysozyme in a cellulose based paper pulp was optimized using the experimental design methodology. A Face-Centered Composite design was applied to investigate the effect of short/long fibers ratio and carboxymethyl cellulose concentration on linking lysozyme to the fibers surface and to optimize the cellulosic matrix composition. The related polynomial model showed good fitting ability $\left(\mathrm{R}^{2}>0.9\right)$ as well as good prediction ability $\left(\mathrm{Q}^{2}>0.8\right)$. The best combination of factors was $50 \%$ short fibers, $50 \%$ long fibers and at least $4 \%$ carboxymethyl cellulose. Afterwards the lysozyme release was investigated using a mathematical model based on Fick's second law. It was able to describe the release kinetics of lysozyme from the paper sheets made with the optimized cellulosic matrix into water at different temperatures (between 4 and $23{ }^{\circ} \mathrm{C}$ ), $\mathrm{pH}$ (from 4 to 7) and $\mathrm{NaCl}$ concentrations (from 0.2 to $2 \mathrm{M})$. The apparent diffusion coefficients for the lysozyme were in the range of $3.1 \times 10^{-16}$
\end{abstract}

E. Mascheroni $(\varangle) \cdot$ S. Limbo $\cdot$ L. Piergiovanni DEFENS, Department of Food, Environmental and Nutritional Science, University of Milan, Via Celoria 2, 20133 Milan, Italy

e-mail: erika.mascheroni@unimi.it

G. Capretti

INNOVHUB, SSCCP, Italian Pulp and Paper Research Institute, Piazza L. da Vinci 16, 20133 Milan, Italy
$6.6 \times 10^{-14}$ and the $\mathrm{E}_{\mathrm{a}}$ value was $22.1 \mathrm{~kJ} / \mathrm{mol}$ at $\mathrm{pH}$ 5 and $\mathrm{NaCl}$ concentration of $0.5 \mathrm{M}$.

Keywords Lysozyme $\cdot$ Cellulose $\cdot$ Active packaging material $\cdot$ Diffusion coefficient

\section{Introduction}

Packaging strategies that contribute actively to food preservation have been recently developed incorporating active compounds into films and coating in order to retard surface growth of bacteria, yeasts, and moulds on a wide range of food products (Ajayan et al. 2007; Nam et al. 2007; Conte et al. 2007; Buonocore et al. 2003; Appendini and Hotchkiss 1997; Mastromatteo et al. 2010). The use of such packaging materials is not meant to be a substitute for good sanitation practices, but it aims to maintain the quality of food and to extend its shelf life, introducing an additional hurdle against the growth of the spoilage microorganisms. The direct surface application of antibacterial substances onto foods is not always possible and, when it is technologically feasible, it has limited benefits because the active substances diffuse rapidly from the surface, where the protection is needed, into the food mass. Putting antimicrobial agents into the packaging, instead, can be more efficient because they are released at a slower rate 
(Pérez-Pérez Ma et al. 2006; Min et al. 2008; Janes et al. 2002; Han et al. 2008); this implies the antimicrobial presence at the food surface for a longer time.

There are different types of antimicrobial molecules that can be combined with packaging materials. Among them, proteins present some interesting properties: they are natural, sometimes they are also food components, they act at low concentrations, are thermostable, and non-volatile. Since antimicrobial proteins are usually charged, significant amounts of proteins can be efficiently incorporated into and/or onto a bio-based packaging material that is hydrophilic and appropriately charged. The unique properties of the hydrophilic cellulose concerning its versatility to be charged, its processability at low temperature combined with its renewable source, biodegradability, and recyclability, seems good reasons to set up a natural active cellulose based system.

Cellulose-based materials can become suitable for this aim through modulation of the charge density of the cellulose matrix. If the antimicrobial protein is cationic, like lysozyme at $\mathrm{pH}$ around neutrality, it could be linked to a cellulosic matrix that is negatively charged. If the charge density of the substrate is not sufficient, it may be increased by introducing polyelectrolytes, such as carboxymethyl cellulose (CMC) (Horvath and Lindström 2007; Laurell 1952; Wiebe and Klug 1957; Laine et al. 2000; Blomstedt et al. 2007), that are also able to enhance paper strength (Duker and Lindstron 2008). A previous study of the same authors (Mascheroni et al. 2010) shows that lysozyme absorption on the paper sheet surface and thermal stability greatly increased by incorporating $\mathrm{CMC}$ into the pergamyn paper.

Moreover, the knowledge of the diffusion process is a key factor in the prediction of the antimicrobial agent release profile from a material as a function of its characteristics and of the surrounding conditions, to determine the time during which the agent remains in the system above its critical effective concentration (Franssen et al. 2004). The possibility of modulating the release kinetics of active compounds such as lysozyme, nisin, and sodium benzoate from biopolymer has been evaluated already (Buonocore et al. 2003; Guillard et al. 2009), but the mechanism of migration from fiber-based materials and from plastics is different. Paper materials are heterogeneous, open and porous structures consisting of cellulosic fibers, air and pores, and the characteristics of the cellulosic fibers are key parameters to take into account in the application of modeling (Pocas et al. 2011; Zulchh and Piringer 2010). Currently, the literature line is to treat, when it is possible, the migration process from paper and board as done with plastic materials (Franz 2002; Crank 1975; Piringer and Baner 2000; Castle 2004). It has been suggested, in fact, that a one-dimensional diffusion process has limitations in describing molecular transfer in dry paper with low porosities and low thickness, for example in the case of greaseproof and glassine paper (Hellén et al. 2002), whereas for paper with high humidity (e.g. humidified by the contact with fresh foods) and in presence of medium or high porosity, a strong increase in the molecules desorption rate occurs. In this case it is possible to use the modeling procedure described for plastic materials also for modeling the mass transfer through paper and board into foodstuff (Zulchh and Piringer 2010).

A first aim of this work will be to evaluate the paper capacity to support lysozyme as a function of the cellulose matrix composition releasing on the experimental design methodology. The capability of lysozyme to endure the stress of papermaking and to retain its antimicrobial activity when it is incorporated in paper sheet will be also verified.

A second aim of this work will be the estimation of the diffusion rate of the antimicrobial proteins through mass transfer model, once a food simulant is in contact with the paper, since an active packaging must remain effective throughout the entire shelf life of the product (Cooksey 2000; Weng and Hotchkiss 1993).

\section{Materials and methods}

Materials

Commercial bleached short (SF) and long (LF) Kraft fibers, separately refined according to ISO 5264-1 at a freeness level of $80^{\circ} \mathrm{SR}$, were used in papermaking. Sodium carboxymethyl cellulose (CMC, WALOCEL CRT 60000 PPA07, DS 0.7-0.8) was from Wolff Cellulosic, Schkopau, Germany. Lysozyme was kindly supplied by Clerici SpA (Cadorago, Italy). Poly diallyldimethyl-ammonium chloride (Poly-Dadmac) and sodium polyethylene sulfonate (PES-Na) were obtained from BTG (Saffle, Sweden). The polyamideamine epichlorohydrin (PAAE) wet strength resin 
(Kemistrength RU20) was kindly donated by Kemind (Parabiago, Italy).

CMC attachment and Poly Electrolyte Particle Charge analysis

The attachment of CMC was carried out according to Laine et al. 2000. The electrokinetic surface charge of the CMC treated fibers was measured by the backtitration method outlined by Wågberg et al. (1989) using a polyelectrolyte particle-charge detector (Mütek PCD 04, Herrsching, Germany) integrated with an automatic titrator (Mütek PCD-T3, Herrsching, Germany). The anionic CMC treated fibers (about $200 \mathrm{mg}$ ) were increasingly saturated with at least six different amounts of Poly-Dadmac and the excess of cationic polymer was titrated with PES-Na $0.001 \mathrm{~N}$. The anionic charge of $\mathrm{CMC}$ was $3,954 \mu \mathrm{eq} / \mathrm{g}$ as determined by direct titration with Poly-Dadmac.

\section{Sheet forming and testing}

Paper sheets were formed with different ratios of short and long kraft fibers and in the absence/presence of different amounts of the anionic polyelectrolyte CMC. Constant amounts of lysozyme ( $10 \mathrm{~g} / 100 \mathrm{~g}$ of fibres) dissolved in a $20 \mathrm{mM}$ phosphate buffer, $\mathrm{pH}$ 7, were put in contact with pulps for $20 \mathrm{~min}$ before papermaking. The pulp consistency was $5 \mathrm{~g} / \mathrm{l}$ and the $\mathrm{pH}$ of the slurry was 7.5. Handsheets with high wet strength were made by adding the PAAE resin $(80 \mathrm{mg} / \mathrm{g}$ of dry fibers) to the pulp slurry under stirring for $15 \mathrm{~min}$ before the adding of lysozyme (100 mg/g of dry fibers).

Paper sheets were prepared by a Rapid Köthen System (HAAGE BBS type, ESTANIT, Mülheim an der Ruhr, Germany), according to the international standard ISO 5269-2:2004. Sheets were wet pressed and dried under restraint and vacuum for $1 \mathrm{~min}$ at $90 \pm 1{ }^{\circ} \mathrm{C}$. The grammage of the sheets was $50 \pm 1 \mathrm{~g} / \mathrm{m}_{2}$, evaluated according to ISO 536:1995. The thickness measured on single sheets of paper was $64 \pm 3 \mu \mathrm{m}$ measured according to ISO 534:2005. The mechanical properties of the handsheets (tensile strength, stretch at rupture and tensile energy absorption (TEA) index were evaluated according to the method ISO 1924-2:2008 with a dynamometer at constant rate of elongation (Acquati G., Arese, Italy mod AG/MC2). The determination of the wet tensile strength of paper after its immersion in water for $2 \mathrm{~h}$ was carried out according to the method ISO 3781:2011. All the tests were performed after conditioning the sheets in standard atmosphere at $23 \pm 1{ }^{\circ} \mathrm{C}$ and $50 \pm 2 \%$ relative humidity.

Experimental design for cellulosic optimization

In order to control the bioactive molecule release, it is necessary to achieve a clear awareness of the effect of the fiber type and the CMC quantity on binding capacity. The Design of Experiment technique (DOE) was used employing a Face-Centered Composite design that support a quadratic model (Kincl et al. 2005; Anderson and Whitcomb 2006). Two quantitative controllable factors (independent variables) were considered for the screening test: short/long fibers ratio $\left(\mathrm{X}_{1}\right)$ and carboxymethyl cellulose concentration (CMC) $\left(\mathrm{X}_{2}\right)$. Each of these independent variables was assessed at two equidistant levels $(-1,+1)$ from the centre point (0). In particular, short/long fibers ratio ranged from 20/80 to 80/20 and CMC quantity from 0 to $10 \%$. The dependent variable selected as responses was the amount of bioactive molecule bound. A $2^{2}$ full factorial design was chosen with 18 total runs ( 6 centre points), in random sequence, in order to avoid any influence of external and/or extraneous factors possibly affecting the results. The worksheet obtained from this design is reported in Table 1. MODDE software package (MODDE 2006, version 8.0; UMETRICS AB, Umea, Sweden) was used for the evaluation of raw data and regression analysis in the screening design.

Lysozyme quantification in paper sheets

An internal method based on the ISO 8968-1:2001 (Kjeldahl method) was used in order to determine the nitrogen content of the paper after the lysozyme sorption. Samples were accurately weighted in order to have about $100 \mathrm{mg}$ of lysozyme inside the digestion flask. The paper was digested with $20 \mathrm{ml}$ of concentrated sulfuric acid $(96 \%)$ in the presence of copper (II) sodium and potassium sulfate. Both distillation and titration were performed by using an apparatus provided with a distillation unit and a potentiometric titrator (BUCHI 339, Italy). The quantification of lysozyme content in each sample was done using the conversion factor nitrogen/protein determined for pure lysozyme (Clerici SpA, Cadorago, Italy). 
Table 1 Worksheet of the $2^{2}$ full factorial design with the variable levels

\begin{tabular}{|c|c|c|}
\hline \multirow{2}{*}{$\begin{array}{l}\text { Exp. } \\
\text { no }\end{array}$} & \multicolumn{2}{|l|}{ Variable Levels } \\
\hline & $\begin{array}{l}\text { Short fiber/long fiber } \\
\left(\mathrm{X}_{1}\right)\end{array}$ & $\begin{array}{l}\text { Carboxymethyl cellulose }(\%) \\
\left(\mathrm{X}_{2}\right)\end{array}$ \\
\hline 1 & $20 / 80$ & 0 \\
\hline 2 & $80 / 20$ & 0 \\
\hline 3 & $20 / 80$ & 10 \\
\hline 4 & $80 / 20$ & 10 \\
\hline 5 & $50 / 50$ & 5 \\
\hline 6 & $50 / 50$ & 5 \\
\hline 7 & $50 / 50$ & 5 \\
\hline 8 & $20 / 80$ & 0 \\
\hline 9 & $80 / 20$ & 0 \\
\hline 10 & $20 / 80$ & 10 \\
\hline 11 & $80 / 20$ & 10 \\
\hline 12 & $50 / 50$ & 5 \\
\hline 13 & $50 / 50$ & 5 \\
\hline 14 & $50 / 50$ & 5 \\
\hline 15 & $20 / 80$ & 5 \\
\hline 16 & $80 / 20$ & 5 \\
\hline 17 & $50 / 50$ & 0 \\
\hline 18 & $50 / 50$ & 10 \\
\hline
\end{tabular}

Estimation of lysozyme released in aqueous solution

The amount of lysozyme released from the cellulose fibers of paper sheets was quantified by using spectrophotometry (Lambda 650, PerkinElmer, Italy). The paper standard samples of $2.54 \mathrm{~cm}^{2}$ of the best composition in terms of lysozyme bound (50\% short fiber, $5 \% \mathrm{CMC}$ added) were put in contact with $7 \mathrm{ml}$ of solution of different $\mathrm{pH}(4-7)$ and $\mathrm{NaCl}$ content (0.2-2 M) under stirring. The effect of temperature (4, 10 and $23{ }^{\circ} \mathrm{C}$ ) was also tested. At fixed time intervals the paper sample was removed and the absorbance of the aqueous solutions was measured at $280 \mathrm{~nm}$ (Selsted and Martinez 1980). A lysozyme calibration curve was prepared by measuring the absorbance of aqueous solutions of the pure enzyme at five different concentrations.

Diffusion models and apparent diffusivity determination

Depending on the assumptions made for the boundary condition at the interface paper/solution and on the ratio of solution volume to the paper sheet volume, alternative models can be applied in order to predict migration inside the paper sheet and to determine the antimicrobial diffusivity (Poças et al. 2008).

In this case, A Fickian formalism with a constant diffusivity that considers finite volume of solution and negligible resistance to the external mass transfer is used. Whatever the boundary hypothesis used for describing the system, the mass conservation equation in the paper sheet can be written as:

$t>0,--\mathrm{L}<\mathrm{x}<+L, \frac{\partial C}{\partial t}=D \frac{\partial^{2} C}{\partial x^{2}}$

where $\mathrm{x}$ is the distance (m), $\mathrm{t}$ is time (s), $\mathrm{C}$ the sheet concentration in migrant ( $\mathrm{kg}$ lysozyme $/ \mathrm{kg}$ of paper), $\mathrm{D}$ the migrant apparent diffusivity within the packaging $\left(\mathrm{m}^{2} / \mathrm{s}\right)$ and $\mathrm{L}$ the half-thickness of the packaging.

The initial concentration $\left(\mathrm{C}_{\mathrm{in}}\right)$ of the migrant in the sheet is considered homogeneously distributed and equal to a constant $\mathrm{C}$ :

$t=0,--\mathrm{L}<\mathrm{x}<+L, C=C_{i n}$

where $\mathrm{C}_{\text {in }}$ is the initial lysozyme concentration in the paper sheet. In our specific case the ratio of solution volume to the paper sheet volume is not high to be considered as infinite; moreover, the liquid is strongly stirred, so there is no boundary resistance for the transfer between paper sheet and water solutions; the diffusion depends only on time, and the total amount of diffusing substance in the sheet and in the liquid remains constant when diffusion proceeds. The balance equation is:

$t>0, \mathrm{x}= \pm L,-D \frac{\partial C}{\partial x}=\frac{V^{L}}{A^{P}} \frac{\partial C}{\partial t}$

where $\mathrm{A}^{\mathrm{P}}$ is the sheet surface area, $V^{L}$ is the volume of solution.

With a constant diffusivity and the condition of the uniform concentration of the diffusing substance in the paper sheet, the kinetics of transport of the substance out of the sheet of half thickness $\mathrm{L}$ is expressed by the following relationship (Crank 1975; Vergnaud and Rosca 2006):

$\frac{M_{t}}{M_{\infty}}=1-\sum_{n=1}^{\infty} \frac{2 \alpha(1+\alpha)}{1+\alpha+\alpha^{2} q_{n}^{2}} \exp \left(-\frac{q_{n}^{2} D t}{L^{2}}\right)$

with $\alpha=\frac{V^{L}}{K_{p l} V^{P}}$ where $V^{P}$ represents the volume of paper and $\mathrm{K}_{\mathrm{pl}}$ the partition coefficient at equilibrium of 
the migrant in the system between the paper and the solution, which can be assumed as constant.

$K_{p l}=\frac{C_{\text {polymer }, \infty}}{C_{\text {liquid }, \infty}}$

$\mathrm{q}_{\mathrm{n}}$ are the non-zero positive roots of :

$\tan q_{n}=-\alpha q_{n}$

The dependency of the apparent diffusion coefficient on temperature is described by the Arrhenius equation and it is used to calculate the value of activation energy ( $E_{a}$, Eq. 7).

$\ln \mathrm{D}=\ln \mathrm{D}_{0}-\left(\mathrm{E}_{\mathrm{a}} / \mathrm{RT}\right)$

where $E_{a}$ is the activation energy for the considered transition and $\mathrm{T}$ is the temperature $(\mathrm{K})$.

Modelling of lysozyme release was performed using the Fickian model (Eq. 4) elaborated by means of MATLAB ${ }^{\circledR}$ software (The Mathworks Inc., Natick, MA, USA). Using Levenberge-Marquardt algorithm (Gill et al. 1981) for optimization procedure, calculation of diffusivity values was conducted for each paper sheet by minimizing the sum of squared error between experimentally measured and predicted values of lysozyme content obtained with Eq. (4).

Theoretical kinetic release was calculated with a half thickness $\mathrm{L}$ of $32.5 \pm 0.5 \mu \mathrm{m}$. The lysozyme initial quantity was deduced from the Kjeldahl determination and was expressed in $\mathrm{kg}$ of lysozyme/ $\mathrm{kg}$ of paper. The partition coefficient of lysozyme in paper/solution, corresponded to the ratio of concentrations of lysozyme in the paper sheet and in the water at equilibrium, was obtained at least after 10 days of contact. Positive roots $\mathrm{q}_{\mathrm{n}}$ in Eq. (6) were calculated by using a routine programmed in MATLAB software.

The root mean square error (RMSE) was used to estimate the quality of model fitting and was calculated as follows:

$R M S E=\sqrt{\frac{(y-y)^{2}}{(N-p)}}$

where $y$ and $\hat{y}$ are respectively the experimental and predicted released lysozyme content, $\mathrm{N}$ is the number of experimental measurements and $p$ the number of estimated model parameters. If RMSE tends toward 0 or is very close to the experimental error, it means that model is able to represent the experimental data.
Antimicrobial activity

The activity of lysozyme after paper sheet production was estimated by lysoplate assay (Li-Chan and Nakai 1986; Brandtzaeg 1972). Micrococcus lysodeikticus ATCC 4698 lyophilized cells (Sigma Aldrich, Italy) were suspended in a $0.1 \mathrm{M}$ buffer phosphate, $\mathrm{pH} 7$ and added to a $10 \mathrm{~g} / \mathrm{l}$ agarose solution. The mixture was boiled and put inside Petri dishes. After cooling, paper samples were deposed on the substrate surface. Lysozyme activity was evaluated after $24 \mathrm{~h}$ incubation at $37{ }^{\circ} \mathrm{C}$ by observing the clarification halo surface around paper due to the lytic activity on the isolated microbial cells.

After that, samples of this active paper $\left(15 \mathrm{~cm}^{2}\right.$, $50 \%$ short fibers, $3.8 \%$ of CMC attached and $72 \%$ of lysozyme attached) were placed in $30 \mathrm{ml}$ of TSB in sterile tubes inoculated ( $1 \% \mathrm{v} / \mathrm{v})$ with a microbial suspension of either E. coli or L. innocua having OD600 $=0.200$. E. coli DSMZ 50902 (DSMZ: Deutsche Sammlung von Mikroorganismen und Zellkulturen GmbH, Braunschweig, Germany) and L. іппосиа DSMZ 20649 were used. Strains were grown on TSA medium (Tryptic Soy Agar, Micropoli, Milan), incubated at $37^{\circ} \mathrm{C}$ for $24 \mathrm{~h}$, and then maintained at $-20{ }^{\circ} \mathrm{C}$ in TSB liquid medium in presence of $10 \%$ (w/v) glycerol. Cultures were propagated twice before use in experiments.

Control cultures, without paper, were also set-up. During incubation at $30{ }^{\circ} \mathrm{C}$, culture samples were taken at appropriate intervals during $24 \mathrm{~h}$, and bacterial population (log cfu/ml) determined employing the plate count technique. Time course of cell growth in each trial was then fitted employing the DMFit software, to estimate growth rate $\left(\mathrm{h}^{-1}\right)$, lag phase duration (h), final population ( $\left.\mathrm{Y}_{\text {end }}, \log \mathrm{cfu} / \mathrm{ml}\right)$, correlation coefficient $\left(\mathrm{R}^{2}\right)$ and model standard error (SEfit), as predicted by the Baranyi and Roberts Equation (1994).

\section{Results and discussion}

Paper binding capacity of lysozyme during sheet forming

CMC attachment, as determined by the back-titration method (Wågberg et al. 1989), resulted in a great increase of the anionic charge density of the cellulosic 


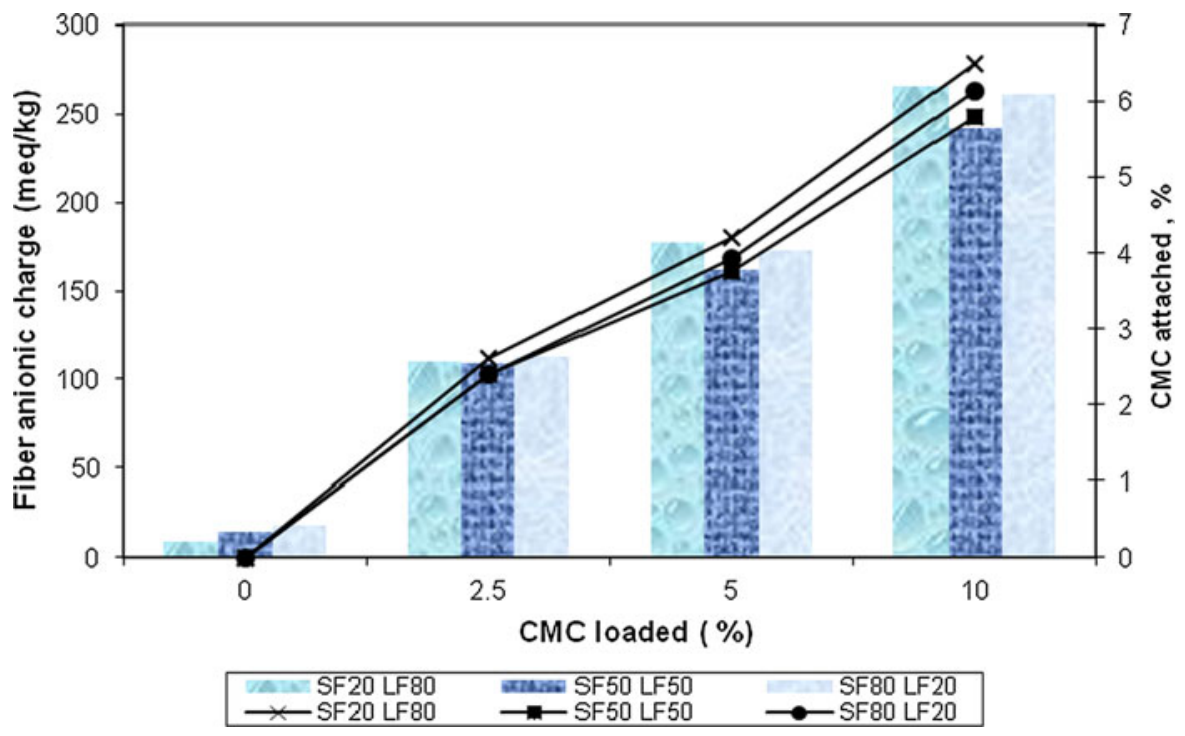

Fig. 1 Anionic charge of the fibres (bars) as determined by the back titration method and attached CMC (points) as a function of the CMC loaded. The amount of CMC attached to the fibres is

fibers. The anionic surface charge of the fibers without CMC was between 9 and $18 \pm 3 \mathrm{meq} / \mathrm{kg}$, depending on the long/short fibers ratio, and it increased with the addition of CMC up to a value of $266 \pm 13 \mathrm{meq} / \mathrm{kg}$ (Fig. 1). The high value of anionic charge density obtained makes this cellulose matrix suitable for a good attachment of the positively charged lysozyme. Moreover, this open structure could promote a large numbers of interactions between the enzyme and the surface charge of cellulosic fibers.

The Design of Experiment technique (DOE) used explains the effect of the fiber type and the CMC percentage on the paper capacity to bind lysozyme. Table 2 summarizes the statistical parameters which are generally recognized as the most important to judge the validity of the experimental model in terms of fitting capability $\left(\mathrm{R}^{2}\right)$, prediction ability $\left(\mathrm{Q}^{2}\right)$, reproducibility, and model validity. These values show that a high percentage of the variation of the

Table 2 Parameters of DOE quality

\begin{tabular}{ll}
\hline Parameter & Value \\
\hline $\mathrm{R}^{2}$ & 0.91 \\
$\mathrm{Q}^{2}$ & 0.81 \\
Reproducibility & 0.86 \\
Model validity & 0.79 \\
\hline
\end{tabular}

calculated by subtracting from the total charge the one initially present on the fibers, and dividing the resulting value by the charge of $\mathrm{CMC}$

response is explained by the model (i.e., the model satisfactorily fits the data), and is predicted by the model (i.e., the model is able to predict the data). The reproducibility is good and also the parameter "model validity" (which is a measure of the lack of fit) has been considered good, because values over 0.25 are normally judged as acceptable. It is also reported the relative analysis of variance (ANOVA) (Table 3). The relationship between short/long fibers ratio and $\mathrm{CMC}$ percentage in defining the lysozyme adsorption response is represented with a response surface contour plot (Fig. 2). This tool is able to indicate the direction towards which the different cellulosic matrices should be set up to bind the desired quantity of lysozyme. In particular, the Fig. 2 shows that in this case an increase in CMC produces an increase in the cellulosic matrix capacity to bind lysozyme until a given value of CMC (around $4 \%$ for medium percentage of short fibers). Above the $4 \%$ threshold, an increase in CMC percentage did not improve paper binding capacity. Under the best combination of factors (the darkness area in the surface contour plot in Fig. 2), the maximum paper binding capacity toward lysozyme was around $72 \%$ with a $28 \%$ of protein losses during the sheet forming at laboratory scale. To complete the understanding of the lysozyme adsorption phenomenon, the same combination of cellulosic material $(50 \%$ short fibers, $4 \%$ of CMC 
Table 3 Analysis of variance table for the response of bound lysozyme

\begin{tabular}{lcccc}
\hline Source of variation & $\begin{array}{l}\text { Degrees of freedom } \\
\text { (DF) }\end{array}$ & $\begin{array}{l}\text { Sum of squares } \\
(\mathrm{SS})\end{array}$ & $\begin{array}{l}\text { Mean square } \\
(\text { MS })\end{array}$ & $\begin{array}{l}\text { The model significance (regression/ } \\
\text { residual) } \\
\text { F ratio }\end{array}$ \\
\hline Total & 18 & 69682.2 & 3871.2 & \\
Constant & 1 & 63158.1 & 63158.1 & 383.8 \\
Total corrected & 17 & 6524.1 & 1178 & 22.2 \\
Regression & 5 & 5890 & 52.8 & 1.1 \\
$\begin{array}{l}\text { Residual } \\
\text { Lack of fit (model } \\
\quad \text { error) }\end{array}$ & 3 & 634.5 & 53.3 & \\
$\begin{array}{l}\text { Pure error (replicate } \\
\quad \text { error) }\end{array}$ & 9 & 159.9 & 52.7 & \\
\hline
\end{tabular}

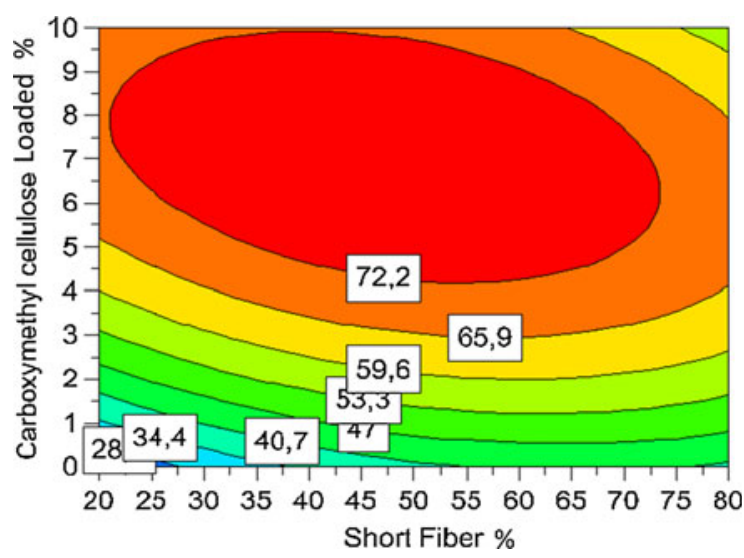

Fig. 2 Response contour plot for short fiber $(\%) \times$ carboxymethyl cellulose $(\%)$; response: bound lysozyme $(\%)$

loaded which corresponds to the $3.8 \%$ of $\mathrm{CMC}$ attached) was placed in contact with different concentrations of lysozyme and bound lysozyme was quantified at equilibrium. As shown in Fig. 3, the matrix saturated at about $200 \mathrm{mg}$ lysozyme/g, likely because of the combined effects of ionic and steric hindrance factors. Behind the evaluation of the paper binding capacity it is also important to verify that the active substance added do not affect the physicochemical properties of the paper for the possibility of a real applications. Table 4 shows the mechanical properties of some papers produced in the presence of CMC and lysozyme. As expected, the tensile strength increased with increasing the long fibers content at constant CMC (Table 4). Furthermore, increasing the $\mathrm{CMC}$ content of paper, at constant fibers composition, the tensile strength and TEA index were improved (see the last 2 columns of Table 4),

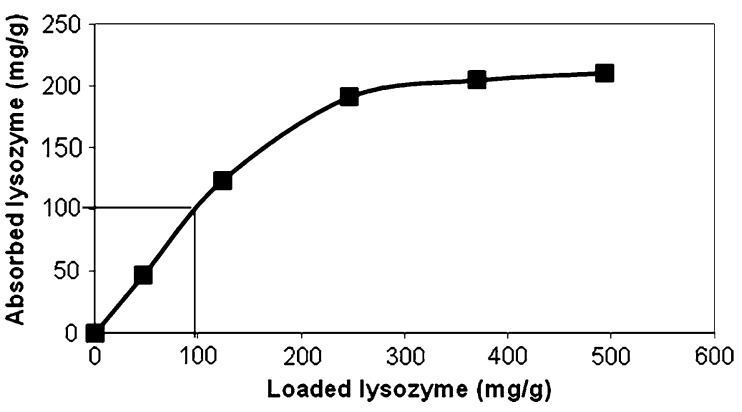

Fig. 3 Lysozyme adsorption from cellulosic matrix as a function of the lysozyme added within $24 \mathrm{~h}$. The composition of the cellulosic matrix was LF $50 \%$, SF $50 \%$, attached CMC $3.8 \%$. The lysozyme absorbed is determined by subtracting from the initial concentration the lysozyme left unbound into the solution. The lysozyme concentration was determined by spectrophotometry at $280 \mathrm{~nm}$

according to previous studies (Laine et al. 2002). The lysozyme application to the system CMC/fibers did not impair the improvement of the paper strength properties. The paper in contact with moist food for several days must be permanently wet strength; otherwise the fibers network disrupts by absorbing water and swelling. The wet/dry tensile strength ratio can be assumed as an index of treatment effectiveness and papers that show wet/dry strength ratio in the range of $20-30 \%$ are considered as "wet strengthened". The papermaking process developed, where PAAE resin was mixed with the fibers in the slurry $(80 \mathrm{mg} / \mathrm{g}$ of dry fibers) together with Lysozyme $(100 \mathrm{mg} / \mathrm{g})$, gave a wet strength of $1200 \mathrm{~N} / \mathrm{m}$ and $27 \%$ of the wet/dry tensile ratio that is an acceptable value for applications in the field of fresh food packaging. 
Table 4 Mechanical properties of paper composed by CMC, short and long fibers and $10 \%$ of lysozyme added

\begin{tabular}{lllllc}
\hline & & SF80 + LF20 $\%$ & SF50 + LF50 \% & SF20 + LF80 \% & SF20 + LF80 \% \\
\hline Attached CMC & $\%$ & $3.9 \pm 0.2$ & $3.8 \pm 0.1$ & $4.2 \pm 0.4$ & $6.5 \pm 0.4$ \\
Dry tensile index & $\mathrm{Nm} / \mathrm{g}$ & $61 \pm 2$ & $70 \pm 2$ & $75 \pm 2$ & $93 \pm 4$ \\
Dry stretch at rupture & $\%$ & $3.3 \pm 0.3$ & $3.2 \pm 0.2$ & $3.8 \pm 0.1$ & $3.6 \pm 0.2$ \\
TEA index & $\mathrm{kJ} / \mathrm{kg}$ & $1.4 \pm 0.1$ & $1.7 \pm 0.1$ & $1.9 \pm 0.1$ & $2.1 \pm 0.2$ \\
\hline
\end{tabular}

Release kinetics of lysozyme from paper sheets and apparent diffusivity values

Fresh and minimally processed food like dairy products, meat, fish and vegetables have a sub-acid $\mathrm{pH}$ and a moderate salt content, and these conditions might influence the release rate and the total amount of lysozyme released from the active packaging during use. This study presents the behavior of lysozyme when the cellulosic matrix is put in contact with a food simulant composed by different water solutions (different $\mathrm{NaCl}$ concentrations and different $\mathrm{pH}$ values). The apparent diffusion coefficients of lysozyme were calculated from the experimental data of lysozyme releasing experiments. The diffusivity determined is an overall transport coefficient that represents the different mechanisms of water transport that prevail in the paper sheet and that were numerically solved by means of Fickian models. In particular, in this case, the liquid becomes saturated of lysozyme as a function of time and the resistance to the mass transfer is negligible thanks to the water solution stirring. The $\mathrm{K}_{\mathrm{pl}}$ values and the resulting apparent diffusivity values $\left(\mathrm{D}_{\mathrm{app}}\right)$ are given in Table 5. Fickian Model succeeded in fitting experimental data on lysozyme release in aqueous solution with RMSE values close or lowers than the experimental error (Table 5). The obtained values of $\mathrm{K}_{\mathrm{pl}}$ and $\mathrm{D}_{\mathrm{app}}$ confirm the dependence of diffusivity on the $\mathrm{NaCl}$ concentration. The apparent diffusion coefficients for the lysozyme diffusion in the paper sheet $\left(D_{\text {app }}\right)$ increases either with increasing ionic concentration or the $\mathrm{pH}$ values of the surrounding environment. At low

Table 5 Apparent diffusivity $\left(D_{\text {app }}\right)$ values of lysozyme and partition coefficient $\left(K_{\mathrm{pl}}\right)$ determined from release experiments conducted in water at different values of $\mathrm{pH}, \mathrm{NaCl}$ concentrations and temperatures

\begin{tabular}{|c|c|c|c|}
\hline $\begin{array}{l}\mathrm{pH} \\
\left(\mathrm{NaCl} \quad 0.5 \mathrm{M}-23{ }^{\circ} \mathrm{C}\right)\end{array}$ & $\mathrm{D}_{\text {app }}\left(10^{-15} \mathrm{~m}^{2} \mathrm{~s}^{-1}\right)$ & RMSE (\%) & $\mathrm{K}_{\mathrm{pl}}$ \\
\hline 4.0 & $1.18(0.70-1.66)^{*} \mathrm{a}$ & 3.2 & 908 \\
\hline 5.0 & $1.41(0.97-1.86) \mathrm{ab}$ & 2.7 & 508 \\
\hline 6.0 & $2.23(0.75-3.7) \mathrm{abc}$ & 6.1 & 284 \\
\hline 7.0 & $13.6(7.5-19.8) \mathrm{d}$ & 3.6 & 159 \\
\hline $\begin{array}{l}\mathrm{NaCl} \\
\left(\mathrm{pH} 5.0-23{ }^{\circ} \mathrm{C}\right)(\mathrm{M})\end{array}$ & $\mathrm{D}_{\mathrm{app}}\left(10^{-14} \mathrm{~m}^{2} / \mathrm{s}\right)$ & RMSE (\%) & $\mathrm{K}_{\mathrm{pl}}$ \\
\hline 0.2 & $0.09(0.02-0.16)^{*} a$ & 3.8 & 980 \\
\hline 0.5 & $1.4(0.7-1.9) \mathrm{b}$ & 3.6 & 536 \\
\hline 1 & $6.0(4.2-7.7) \mathrm{c}$ & 1.8 & 26 \\
\hline 2 & $6.6(3.8-9.4) \mathrm{c}$ & 2.3 & 37 \\
\hline $\begin{array}{l}\text { Temperature }\left({ }^{\circ} \mathrm{C}\right) \\
(\mathrm{NaCl} 0.5 \mathrm{M}-\mathrm{pH} 5.0)\end{array}$ & $\mathrm{D}_{\text {app }}\left(10^{-15} \mathrm{~m}^{2} / \mathrm{s}\right)$ & RMSE (\%) & $\mathrm{K}_{\mathrm{pl}}$ \\
\hline 4 & $0.31(0.21-0.42)^{*} \mathrm{a}$ & 7.5 & 1651 \\
\hline 10 & $0.42(0.26-0.57) \mathrm{ab}$ & 8.5 & 1321 \\
\hline 23 & $1.41(0.97-1.86) \mathrm{c}$ & 2.7 & 538 \\
\hline
\end{tabular}

Values with the same letters are not significantly different

* In brackets, $95 \%$ confidence intervals of diffusivity 
Fig. 4 Lysozyme release kinetics obtained for paper sheets, composed by $50 \%$ short fibres and $3.7 \% \mathrm{CMC}$, at $4{ }^{\circ} \mathrm{C}(\mathrm{O}), 10{ }^{\circ} \mathrm{C}(\Delta)$ and $23{ }^{\circ} \mathrm{C}(*)$ in water solution (pH 5 and $\mathrm{NaCl} 0.5 \mathrm{M}$ ). Symbols are experimental data points. Error bars represent standard deviation. Dot lines are fitting to the model

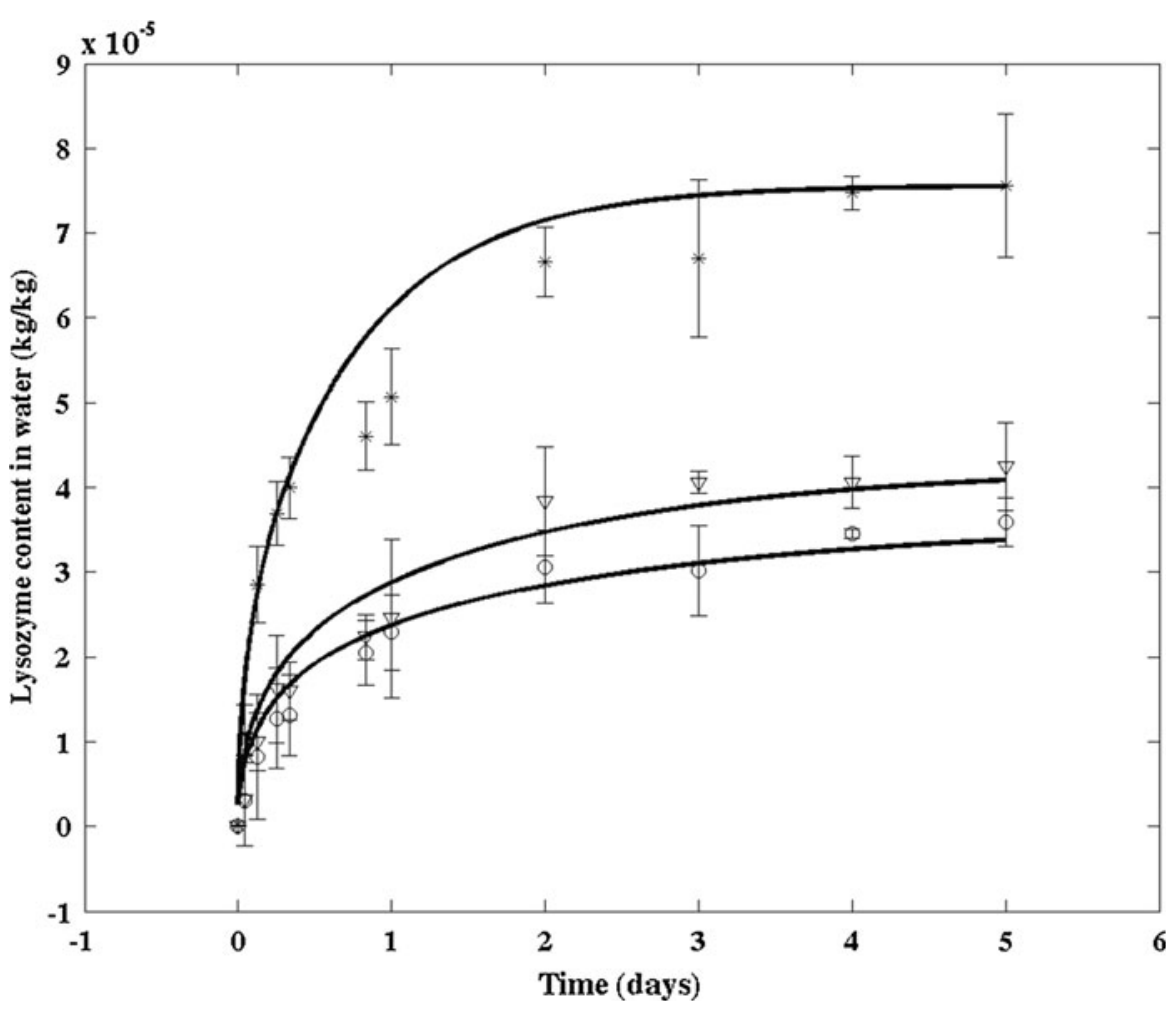

$\mathrm{pH}$ and low ionic strength lysozyme is highly positively charged and is strictly bound to the anionic charge of CMC (and of other cellulosic fibers). The apparent diffusion coefficients obtained are comparable with $D_{\text {app }}$ values of lysozyme release from hydrophilic polymer like PVOH (Buonocore et al. 2003). The $\mathrm{D}_{\text {app }}$ values for lysozyme in cellulosic sheets are over two orders of magnitude smaller than the $\mathrm{D}_{\text {app }}$ values for lysozyme reported in literature for food products like salmon fish (Min et al. 2008). Thanks to this controlled release packaging system, the minimum inhibitory lysozyme concentration at the food surface can be maintained much longer than if an equivalent amount of lysozyme is directly applied on the food surface. The cellulosic paper sheets containing lysozyme may thus be regarded as an appropriate example of antimicrobial controlled release system. The apparent diffusion coefficients $\left(D_{\text {app }}\right)$ were calculated also as a function of temperature to simulate the diffusivity of the antimicrobial compound at different storage temperatures. The curves shown in Fig. 4 were obtained by fitting Eqs. (4-6) to the experimental data. The resulting diffusion coefficients and partition coefficients for the bioactive antimicrobial proteins are listed in Table 5 . Also in this case the proposed model satisfactorily fits the experimental data and shows that the lysozyme is released more quickly when packages are accidentally thermally abused. Faster release of lysozyme at higher temperatures should help in maintaining the microbial charge low on the food surface against lysozyme sensitive microorganisms when microbial growth is facilitated by increased temperature. The Ea associated with lysozyme diffusion in the paper sheet was calculated to be $22.1 \mathrm{~kJ} / \mathrm{mol}$, again comparable with the values reported for lysozyme diffusion in bio-based polymers like whey proteins films (Min et al. 2008).

Antimicrobial activity of incorporated lysozyme in paper sheets

Lysozyme is able to hydrolyze the peptidoglycan wall of gram + bacteria making the cell walls and the membranes break. To evaluate the presence of lysis induced by lysozyme, M. lysodeikticus cells are usually used as representative to test the activity of this antimicrobial compound (Liao et al. 2001). In this 


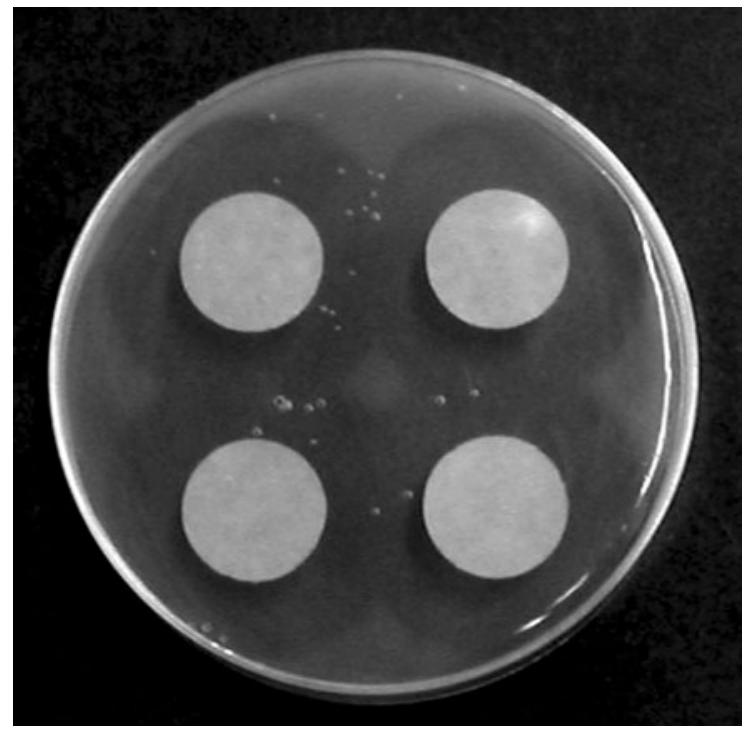

Fig. 5 Lytic activity of lysozyme against M. lysodeikticus, $27 \mathrm{~h}$ at $37^{\circ} \mathrm{C}$ evaluated as inhibition halo

case the paper composed by $50 \% \mathrm{SF}, 50 \% \mathrm{LF}, 3.8$ $\mathrm{CMC}$ and lysozyme resulted suitable to inhibit the growth of M. lysodeikticus; in fact, the inhibition halo is evident around the paper disks with a diameter of $48.5 \pm 1.5 \mathrm{~mm}$ with a paper disk of $26 \mathrm{~mm}$ diameter (Fig. 5). It means that the quantity of lysozyme in paper and the release rate are appropriated to hydrolyze the cell walls and to break the cells. These results underlined also that the enzyme maintain a antimicrobial activity until the package use, despite the process conditions during the papermaking process (agitation, vacuum, drainage and drying temperature) and the storage at ambient conditions for several days. To provide some quantitative data, paper sheets with lysozyme were assessed by microbiological trials, against L. innocua and E. coli, chosen as indicator strains of Gram-positive and Gram-negative bacteria, respectively. Tables 6 and 7 show the efficacy of the paper samples with and without lysozyme against the two microrganisms. The lysozyme-containing paper proved effective in increasing lag phase of $L$. innocua from 1.86 to $5.90 \mathrm{~h}$; then cells started growing faster than the control (Growth rate 0.70 instead of $0.48 \mathrm{~h}^{-1}$ ) and reached $8.50 \log \mathrm{cfu} / \mathrm{ml}$, with a final $0.5 \mathrm{log}$ reduction. Instead, lysozyme-containing paper produced only a modest inhibitory effect against $E$. coli. Growth rate was similar to control, and a modest increase of the lag phase from 1.08 to $1.82 \mathrm{~h}$ resulted in a decimal reduction of only $0.25 \mathrm{log} \mathrm{cfu} / \mathrm{ml}$ with respect to the control. These data were expected because the muramidase activity of lysozyme against Gram-negative bacteria is reported very low.

\section{Conclusions}

Cellulose-based packaging has high and unexploited potential for food applications. This study provides an example of sustainable and active cellulose-based food packaging material. In particular, this work shows the possibility to confer natural active properties to common cellulose based materials without changing their mechanical and physical properties. The study shows that lysozyme loaded into the pulp slurry together with $\mathrm{CMC}$ does not hinder the dry strength of paper; also the wet strength is maintained, suggesting that lysozyme does not interfere with the wet strengthening process.

This system can be employed for bioactive food packaging applications, like pads or wrappings easily usable for extending the shelf life of fresh foods. The adopted approach proved its potential as for simulating the behavior of an active packaging in real working conditions and for designing new materials. Antimicrobial proteins can be loaded according to the needs, by modulating the anionic charge density of the matrix; this parameter may also be fine-tuned to allow controlled release of the adsorbed molecules according

Table 6 Growth rate, lag phase duration, and final population at $24 \mathrm{~h}$ by L. innocua DSMZ 20649, as predicted by the model of Baranyi and Roberts in the presence of paper (50\% SF, $50 \% \mathrm{LF}$ and $3.8 \%$ CMC added, containing $10 \%$ lysozyme added)

\begin{tabular}{|c|c|c|c|c|c|c|}
\hline Protein incorporated & $\begin{array}{l}\text { Duration of the lag phase } \\
\text { (h) }\end{array}$ & $\begin{array}{l}\text { Growth rate } \\
\left(\mathrm{h}^{-1}\right)\end{array}$ & $\begin{array}{l}\text { Yend (log cfu/ } \\
\mathrm{ml})\end{array}$ & $\mathrm{R}^{2}$ & SE fit & $\begin{array}{l}\text { Decimal } \\
\text { reduction }\end{array}$ \\
\hline $\begin{array}{l}\text { Control (paper sheet without } \\
\text { lysozyme) }\end{array}$ & $1.86 \pm 0.3$ & $0.48 \pm 0.05$ & $9.08 \pm 0.02$ & 0.994 & 0.158 & - \\
\hline Paper sheet with lysozyme & $5.90 \pm 0.1$ & $0.70 \pm 0.03$ & $8.50 \pm 0.04$ & 0.993 & 0.211 & -0.55 \\
\hline
\end{tabular}

The correlation coefficient $\mathrm{R}^{2}$ and standard error SE fit are shown. Decimal reduction was computed with respect to control 
Table 7 Growth rate, lag phase duration, and final population at $24 \mathrm{~h}$ by E. coli DSMZ 50902, as predicted by the model of Baranyi and Roberts in the presence of paper (50\% SF, $50 \% \mathrm{LF}$ and $3.8 \%$ CMC added, containing $10 \%$ lysozyme added)

\begin{tabular}{|c|c|c|c|c|c|c|}
\hline Protein incorporated & $\begin{array}{l}\text { Duration of the } \\
\text { lag phase (h) }\end{array}$ & $\begin{array}{l}\text { Growth rate } \\
\left(\mathrm{h}^{-1}\right)\end{array}$ & $\begin{array}{l}\text { Yend } \\
(\log \mathrm{cfu} / \mathrm{ml})\end{array}$ & $\mathrm{R}^{2}$ & SE fit & $\begin{array}{l}\text { Decimal } \\
\text { reduction }\end{array}$ \\
\hline Control (paper sheet without lysozyme) & $1.08 \pm 0.3$ & $0.51 \pm 0.05$ & $9.20 \pm 0.02$ & 0.994 & 0.128 & - \\
\hline Paper sheet with lysozyme & $1.82 \pm 0.4$ & $0.45 \pm 0.03$ & $8.90 \pm 0.04$ & 0.993 & 0.179 & -0.25 \\
\hline
\end{tabular}

The correlation coefficient $\mathrm{R}^{2}$ and standard error SE fit are shown. Decimal reduction was computed with respect to control

to the peculiar physicochemical properties of the packaging food system $(\mathrm{pH}$, ionic strength, temperature). In particular, the wet strength of these paper sheets permits their use with fresh food with high relative humidity: the paper is humidified by the contact with the food and the molecule desorption occurs. For this system is possible to modeling the mass transfer through Fick's second law models that are commonly used for modeling mass transfer through plastic materials. The kinetic results are also supported by the evidences in microbiological tests that showed as this paper is active against L. innocua and, partially, against E. coli, indicator strains of Gram + and Grambacteria. In conclusion, the experimental design used and the kinetic modeling allow to predict the optimum cellulose matrix composition, the initial concentration of lysozyme to be incorporated into paper sheet, and the time period during which growth of target microorganism could be inhibited. However, the spectrum of lysozyme activity is not so wide; further investigation should be done concerning some potential combination of lysozyme with other antimicrobial molecules such as other proteins or polyphenol compounds to obtain the desired antimicrobial and antioxidant activity in a given target food product for a specific time.

Acknowledgments The authors would like to thank the European Commission for the financial support within the NAFISPACK project, 7 Framework. In particular, authors wish to acknowledge Professors Francesco Bonomi and Stefania Iametti of DISMA, University of Milan, for their constructive comments on this paper, and the CNR, section dairy product and Dott.ssa Rollini Manuela of DEFENS, University of Milan, for microbiological tests.

\section{References}

Ajayan V, Masahiko M, Kazi Zakir H, Motoi T, Veerappan VB, Toshiyuki M, Katsuhiko A (2007) Lysozyme adsorption onto mesoporous materials: effect of pore geometry and stability of adsorbents. J Nanosci Nanotechnol 7:828-832

Anderson MJ, Whitcomb P (2006) Design of experiment for coatings. In: Tracton AA (ed) Coating technology handbook. CRC Press, Boca Raton, p 15-1/15-6

Appendini P, Hotchkiss JH (1997) Immobilization of lysozyme of food contact polymers as potential antimicrobial films. Packag Technol Sci 10:271-279

Baranyi J, Roberts TA (1994) A dynamic approach to predicting bacterial growth in food. Int J Food Microbiol 23:277-294

Blomstedt M, Mitikka-Eklund M, Vuorinen T (2007) Simplified modification of bleached softwood pulp with carboxymethyl cellulose. Appita 60(4):309-314

Brandtzaeg P (1972) The 'lysoplate' method for quantification of muramidase activity. Scand J Dent Res 80:166-167

Buonocore GG, Del Nobile MA, Panizza A, Corbo MR, Nicolais L (2003) A general approach to describe the antimicrobial agent release from highly swellable films intended for food packaging applications. J Controlled Release 90:97-107

Castle L (2004) Migration from recycled paper and board to dry foods. Research into the factors involved, leading to practical avoidance and amelioration measures. Report FD 04/07. CSL, York

Conte A, Bonocore GG, Sinigaglia M, Del Nobile MA (2007) Development of immobilized lysozyme based active film. J Food Eng 78:741-745

Cooksey K (2000) Utilization of antimicrobial packaging films for inhibition of selected microorganism. In: Risch SJ (ed) Food packaging: testing methods and applications. American Chemical Society, Washington, DC, pp 2754-2757

Crank J (1975) The mathematics of diffusion. Clarendon Press, Oxford, p 414

de Pocas MF, Oliveira JC, Pereira JR, Brandsch R, Hogg T (2011) Modelling migration from paper into a food simulant. Food Control 22:303-312

Duker E, Lindstron T (2008) On the mechanism behind the ability of CMC to enhance paper strength. Nord Pulp Pap Res J 23:57-64

Franssen LR, Rumsey TR, Krochta JM (2004) Whey protein film composition effects on potassium sorbate and natamycin diffusion. J Food Sci 69(5):C347-C350

Franz R (2002) Programme on the recyclability of food-packaging materials with respect to food safety considerations: polyethylene terephtalate (PET), paper and board, and plastics covered by functional barriers. Food Addit Contam 19(Supplement):93-110

Gill PE, Murray W, Wright MH (1981) Practical optimization. Academic Press, London 
Guillard V, Issoupov V, Redl A, Gontard N (2009) Food preservative content reduction by controlling sorbic acid release from a superficial coating. Innov Food Sci Emerg Technol 10(1):108-115

Han J, Castell-Perez ME, Moreira RG (2008) Effect of food characteristics, storage conditions, and electron beam irradiation on active agent release from polyamide-coated LDPE films. J Food Sci 73(2):E37-E43

Hellén EKO, Ketoja JA, Niskanen KJ, Alava MJ (2002) Diffusion through fibres networks. J Pulp Pap Sci 28(2):55-61

Horvath AE, Lindström T (2007) Indirect polyelectrolyte titration of cellulosic fibers: surface and bulk charges of cellulosic fibers. Nord Pulp Pap Res J 22(1):87-92

Janes ME, Kooshesh S, Johnson MG (2002) Control of Listeria monocytogenes on the surface of refrigerated, ready to eat chiken coated with edible zein film coatings containing nisin and/or calcium propionate. J. Food Sci 67(7): 2754-2757

Kincl M, Turk S, Vrecer F (2005) Application of experimental design methodology in development and optimization of drug release method. Int J Pharm 291:39-49

Laine J, Lindstrom T, Nordmark G, Risinger G (2000) Studies on topochemical modification of cellulosic fibres. Part 1 . Chemical conditions for the attachment of carboxymethyl cellulose onto fibres. Nord Pulp Pap Res J 15:520-526

Laine J, Lindstrom T, Nordmark G, Risinger G (2002) Studies on topochemical modification of cellulosic fibers. Part 2. The effect of carboxymethyl cellulose attachment on fiber swelling and paper strength. Nord Pulp Pap Res J 17(1): $50-56$

Laurell L (1952) Retention of sodium carboxymethyl cellulose in wood pulp. Svensk Papperstidn 55(10):366

Liao Y-H, Brown MB, Martin GP (2001) Turbidimetric and HPLC assays for the determination of formulated lysozyme activity. J Pharm Pharmacol 53:549-554

Li-Chan E, Nakai B (1986) Process for isolation of lysozyme and avidin from egg white. J Food Sci 51:1032-1036

Mascheroni E, Capretti G, Marengo M. Iametti S, Mora L, Piergiovanni L, Bonomi F (2010) Modification of cellulosebased packaging materials for enzyme immobilization. Packag Technol Sci 2347-2357
Mastromatteo MC, Mastromatteo M, Conte A, Del Nobile MA (2010) Advances in controlled release device for food packaging applications. Trends Food Sci Technol 21: 591-598

Min S, Rumsey TR, Krochta JM (2008) Diffusion of the antimicrobial lysozyme from a whey protein coating on smoked salmon. J Food Eng 84:39-47

Nam S, Scanlon MG, Han JH, Izydorczyk MS (2007) Extrusion of pea starch containing lysozyme and determination of antimicrobial activity. J Food Sci 72(9):E477-E484

Pérez-Pérez MC, Regalado-González C, Rodríguez-Rodríguez CA, Barbosa-Rodríguez JR, Villaseñor-Ortega F (2006) Incorporation of antimicrobial agents in food packaging films and coatings. In: Ramón Gerardo, Guevara-González, Irineo Torres-Pacheco (eds) Advances in agricultural and food biotechnology, pp 193-216

Piringer OG, Baner AL (2000) Plastic packaging materials for food-barrier function, mass transport, quality assurance and legislation. In: Piringer OG, Baner AL (eds) Wily$\mathrm{VCH}$, Weimheim

Poças MF, Oliveira JC, Oliveira FAR, Hogg T (2008) A critical survey of predictive mathematical models for migration from packaging. Crit Rev Food Sci Nutr 48(10):913-928

Selsted ME, Martinez RJ (1980) A simple and ultrasensitive enzymatic assay for the quantitative determination of lysozyme in the picogram range. Anal Biochem 109(1): $67-70$

Vergnaud JM, Rosca ID (2006) Assessing food safety of polymer packaging. Rapra Technology, pp 21-36

Wågberg L, Ödberg L, Glad-Nordmark G (1989) Charge determination of porous substrates by polyelectrolyte adsorption, part 1: carboxymethylated, bleached fibers. Nordic Pulp Paper Res J 4(2):71-73

Weng YM, Hotchkiss JH (1993) Anhydrides as antimycotic agents added to polyethylene films for food packaging. Packag Technol Sci 6(3):123-128

Wiebe AK, Klug ED (1957) Sodium carboxymethyl cellulose retention by wood pulp. Tappi 40(3):197

Zulchh A, Piringer O (2010) Measurement and modelling of migration from paper and board into foodstuffs and dry food stimulants. Food Addit Contam 27(9):1306-1324 